\title{
Asymptomatic Carriage of Chlamydia trachomatis Among Young Adults in Owerri, South East Nigeria
}

\author{
Chika Paulinus Enwuru ${ }^{1}$, Sarah I. Umeh ${ }^{2}$ \\ 1. Imo State College of Nursing and Health Sciences Amaigbo, Nigeria \\ 2. Department of Microbiology, Federal University of Technology, Owerri, Nigeria
}

\begin{abstract}
Chlamydia is one of the most common bacterial sexually transmitted infections. A good number of chlamydial infections in men and women may be asymptomatic and remain undiagnosed and untreated. This could result in cervicitis, endometritis, salpingitis, pelvic inflammatory disease, ectopic pregnancy or tubal factor infertility in women and inflammation of the prostate, testicles and subsequently infertility in men. A study was conducted to determine the presence of Chlamydia trachomatis among asymptomatic young male and females. The test was performed by detecting Chlamydia trachomatis $\operatorname{Ig} G$ in the serum of the patients by solid phase Enzyme Immuno Assay. One hundred and fifty males and 150 females aged 15-35 were tested. The prevalence rate of Chlamydia trachomatis among the studied population was $6.7 \%$. Females had prevalence rate of $8.7 \%$ while males had $4.7 \%$. The age ranges 20-24 and 25-29 had higher prevalence. Sexually transmitted Chlamydia trachomatis infections is present asymptomatically among young men and women in the studied population and that could portend danger to the fertility potentials of these men and women. We suggest that routine screening of sexually active young men and women for Chlamydia be undertaken and positive cases treated accordingly. Enlightenment for Safe sex practices is also advocated.
\end{abstract}

Key words: Chlamydia, IgG, Infertility, Sexually transmitted infections,

\section{Introduction}

Chlamydias are obligate intracellular parasites [1]. They are small with gram negative wall and pleomorphic in morphology, requiring certain metabolic constituents of the host for growth and maintenance [2].

Chlamydia is classified into three main medically important species namely: Chlamydia psittaci that causes a zoonotic disease of birds called ornithosis, Chlamydia pneumoniae which causes atypical pneumonia and Chlamydia trachomatis which possesses two important strains, one causing infection in the eye, genitourinary tract and lungs. The second strain causes Lymphogranuloma Venerium (LGV). It attacks the lymphatics of the genitalia. Chlamydia trachomatis is further divided into 15 serological variants. Serovars L1, L2 and L3 are the causes of Lymphogranuloma Venerium, serovars A, B1, B2 and C are the causes of conjunctivitis while serovars D, E, F, G, H I, J and K cause sexually transmitted infections in adults [3], neonatal pneumonia and inclusion conjunctivitis [4]. A fourth species, Chlamydia pecorum has also been described, occurring in the stomach of ruminants [5].

Chlamydia was first isolated from the cervix of the mother of a baby suffering from ophthalmia neonatorum [6]. The reservoir of Chlamydia infection is man. About $10 \%$ of people carry Chlamydia in their genitalia. It was reported that $70-80 \%$ of infected females and $10-50 \%$ of infected males are asymptomatic $[7,8]$. Chlamydia infection mimic gonorrhea hence the infection in men is often referred to as non-gonococcocal urethritis (NGU) and epididymitis with purulent discharge. It could also occur as mixed infection with gonorrhea and other sexually transmitted pathogens. In females, the infection presents as cervicitis, endometritis and salphingitis which eventually results to pelvic inflammatory disease (PID) $[9,10,11]$. The scenario leads to devastating effects of infertility and ectopic pregnancy [7, 12]. It has variously been reported that Chlamydia could predispose to cancer [13], pre term delivery, premature rupture of membrane, low birth weight and still birth [14]. In men, untreated infections can cause inflammation of the testicles and prostate which can also lead to infertility $[15,16]$.

In Lymphogranuloma venerium, the Chlamydia invades the external genitalia, the anus, rectum and inguinal lymph nodes [17]. The portal of entry is tiny nicks in the genitalia or breaks in the perigenital skin and mucous membranes. Small painless vesicular lesion may be formed which may pass unnoticed. A chronic deforming oedema of the genitalia and anus results from the obstruction of lymphatic channels by scare from healed burst buboes. These buboes were formed when lymph nodes near lesions become filled with granuloma cells.

Chlamydia is endemic all over the world. WHO in 2001 reported 90 million cases of Chlamydia worldwide [18] and 215 million in 2011 [19], resulting to about 1200 deaths [20]. According to the Center for Disease Control and Prevention, in 2011, 1.4 million Chlamydia infections were reported in the United States of 
America [21]. The rate of cases per 100,000 increased 8\% to 457.6 in 2011 from 423.6 in 2010. This further increased in 2012 to 643.3 in females and 262.6 in males.

Several methods are available for the laboratory diagnosis of Chlamydia.

Direct staining: Infections of the conjunctiva can be diagnosed by the detection of typical intracytoplasmic inclusions in direct stains like Giemsa, iodine, or cytological staining. According to Chernesky [11], Cytological testing to detect inclusions is particularly useful in diagnosing acute inclusion conjunctivitis of the newborn; the sensitivity of this method exceeds $90 \%$. But the test is relatively insensitive when diagnosing adult conjunctival and genital tract infections.

Cell culture: Culture is the only procedure that confirms the presence of viable organisms. The presence of antigens, nucleic acids or antibodies do not confirm the presence of viable infectious particles. Cell cultures used for Chlamydia trachomatis include McCoy, HEp-2 and HeLa cells [11]. Isolation of Chlamydia trachomatis in cell culture is very expensive, time consuming and requires high technical skills.

Antigen/antibody detection: Several immunoassay-based tests are available, which are based on monoclonal antibody binding of chlamydial antigens from patients' samples or genus-specific antigens for identification and quantification of anti Chlamydia trachomatis antibodies in patients' serum. These rapid tests provide results in a short time of testing and are less expensive to perform and simple to interpret.

Nucleic acid amplification \{NAAT\} involves amplifying Chlamydia trachomatis DNA or RNA sequences using polymerase chain reaction $\{\mathrm{PCR}\}$, transcription-mediated amplification $\{\mathrm{TMA}\}$, or strand displacement amplification $\{$ SDA $\}$. The test is very sensitive and specific but too expensive for use in resourcelimited settings.

Although there have been various reports of the prevalence of Chlamydia in various cities of Nigeria $[23,24,25,26]$, there is paucity of information about Chlamydia infection among the residents of Owerri Southeast Nigeria. This study was therefore conducted to examine the presence of Chlamydia trachomatis among young adults in Owerri, South-east Nigeria.

\subsection{The study area}

\section{Methodology}

The study area is Owerri, the capital city of Imo State, South-east Nigeria. Owerri is known for high social activities with high concentration of higher educational institutions, numerous hospitality industry and governmental and non-governmental agencies that attract people from all walks of life to the city.

\subsection{The Study sample}

The study sample consists of 150 young women and 150 young men of age 15-35 who attend a diagnostic laboratory in Owerri for cases not related to uro-genital tract infections. The patients were counseled and those who consented were enrolled into the study. The blood sample was collected by approved technique and the serum separated after centrifugation [27].

\subsection{Method of testing}

The testing was performed using ImmunoComb Chlamydia trachomatis IgG kit, an indirect solid phase Enzyme Immuno Assay (EIA) which employs broadly cross reacting L2 serotype genus-specific antigens for identification and quantification of anti Chlamydia trachomatis IgG antibodies.

\subsubsection{Kit contents:}

CARDS: The kit contains 3 plastic cards, each card has 12 teeth. One tooth for each test. Each tooth is sensitized with 2 reactive areas: upper spot contains goat antibodies to human immunoglobulin \{internal control\}; lower spot contains inactivated antigens of Chlamydia trachomatis. The cards are provided in aluminum pouches containing a desiccant bag.

DEVELOPING PLATES: The kit contains 3 developing plates covered with aluminum foil. Each developing plate contains all reagents needed for the test.

CONTROLS: The kit also has positive and negative controls.

\subsubsection{Test Procedure}

The test was performed at room temperature according to the manufacturer's instructions as follows:

2.3.2.1. All components of the kit and specimen were brought to room temperature.

2.3.2.2. The developing plate was incubated at $37^{\circ} \mathrm{C}$ for 30 minutes.

2.3.2.3. The reagents were mixed by shaking the developing plates.

2.3.2.4. The aluminum pouch of the card was torn to remove the card taking precaution not to touch the teeth of the card.

2.3.2.5. The foil covers of the wells of row A was perforated using the perforator provided. 
2.3.2.6. Ten microlitres of each specimen was introduced into a well of the row $\mathrm{A}$ of the developing plate.

2.3.2.7. This procedure was carried out for each specimen and both positive and negative controls in different wells using different pipette tips for each specimen or controls.

2.3.2.8. The card \{with printed side facing the researcher\} was inserted into the wells of row A. Homogeneity was achieved by withdrawing and re-inserting the comb several times.

2.3.2.9. The card was left in Row A for 10 minutes.

2.3.2.10. The wells of row B were perforated; the card was removed from row A, the pointed tips of the comb was touched on a clean absorbent paper.

2.3.2.11. The card was inserted into the well of row $\mathrm{B}$, vigorously withdrawn and re-inserted and left for 2 minutes \{first washing $\}$, the wells of row $\mathrm{C}$ were perforated.

2.3.2.12. The card was removed, adsorbed on a clean absorbent paper and inserted into the wells of row $\mathrm{C}$, mixed and left for 20 minutes; the wells of row D were perforated.

2.3.2.13. Second and third washings: the above procedures were carried out in rows $\mathrm{D}$ and $\mathrm{E}$ for 2 minutes each as second and third washings respectively.

2.3.2.14. Colour reaction: the wells of row $\mathrm{F}$ were perforated and the card inserted, mixed and left for 10 minutes.

2.3.2.15. Stop reaction: the card was withdrawn from row $\mathrm{F}$, adsorbed and returned to row $\mathrm{E}$ for 1 minute. This was withdrawn and left to dry in the air.

2.3.3. Reading and Interpretation of result

Reading and interpretation of result is by semi quantitative visual reading. The level of species-specific anti chlamydial IgG in each specimen was assessed by comparing the colour intensity of the lower spot on each tooth with the colour scale on the comb scale provided with the kit after calibration. The scale was calibrated as follows:

2.3.3.1. The lower spot on the positive control tooth was placed underneath the most similar colour intensity of the colour scale. The ruler was adjusted so that $1 / 32, \mathrm{C}+$ appears in the window above the selected colour intensity.

2.3.3.2. The results of the test were read without changing the calibrated position of the ruler. The colour of each lower spot was matched with the most similar intensity on the colour scale. The value displayed in the window above that intensity was recorded as approximate titre of $\operatorname{IgG}$ antibodies to Chlamydia trachomatis for the corresponding specimen.

Table 1: Interpretation of results

\begin{tabular}{|l|l|}
\hline ImmunoComb Titre & Interpretation \\
\hline$<1: 16$ & Negative \\
$1: 16$ & Weakly positive \\
$\geq 1: 32$ & Positive \\
\hline
\end{tabular}

\section{Results}

Out of the 150 males tested, $7\{4.7 \%\}$ have anti Chlamydia trachomatis $\operatorname{IgG}$ antibody titre of 1:32 and above $\{$ table 2$\}$ and were therefore positive for active Chlamydia trachomatis infection.

However, $6\{4.0 \%$ \} samples have titres of 1:16 \{weakly positive\} while $137\{91.3 \%\}$ have titres of $<1: 16$ and were negative for anti Chlamydia trachomatis antibodies.

Men in the age range 25-29 years were more infected $\{10.0 \%\}$ while the age range 15-19 years were not infected at all.

Thirteen $\{8.7 \%\}$ of the 150 females tested were positive for anti Chlamydia trachomatis $\operatorname{IgG}$ with titres of $\geq$ $1: 32$ \{Table 2$\}, 10\{6.0 \%$ \} have titres of 1:16 \{weakly positive\} while $127\{84.7 \%$ \} were negative with titres less than 1:16 \{table 3$\}$.

Young females in the age ranges of 20-24 and 25-29 years have more prevalence of Chlamydia trachomatis $\{13.3 \%\}$ while women in the age ranges $15-19$ and $35-39$ have the least prevalence $\{3.33 \%\}$.

Table 2. Age Distribution of Chlamydia trachomatis IgG

\begin{tabular}{lllllll} 
& $15-19$ & $20-24$ & $25-29$ & $30-34$ & $35-40$ & Total \\
\hline $\mathrm{M}$ & $0 / 30(0 \%)$ & $2 / 30(6.7 \%)$ & $3 / 30(10.0 \%)$ & $1 / 30(3.3 \%)$ & $1 / 30(3.3 \%)$ & $7 / 150(4.7 \%)$ \\
& & & & & & \\
$\mathrm{F}$ & $1 / 30(3.3 \%)$ & $4 / 30(13.3 \%)$ & $4 / 30(13.3 \%)$ & $3 / 30(10.0 \%)$ & $1 / 30(3.3 \%)$ & $13 / 150(8.7 \%)$ \\
\hline
\end{tabular}

$\mathrm{M}=$ males

$\mathrm{F}=$ Females 


\section{Table 3. Anti Chlamydia. trachomatis titres}

\begin{tabular}{llllllr} 
& $<1: 16$ & $1: 16$ & $1: 32$ & $1: 64$ & $1: 128$ & $1: 256$ Total \\
\hline M 137 & 6 & 3 & 3 & 1 & 0 & 150 \\
F 127 & 10 & 5 & 6 & 0 & 2 & 150 \\
\hline
\end{tabular}

$\mathrm{M}=$ males

$\mathrm{F}=$ Females

\section{Discussion}

The overall prevalence of Chlamydia trachomatis in the population studied was $6.7 \%$. Females were more infected $\{8.7 \%\}$ than males $\{4.7 \%$. Females in the age ranges 20-24 and 25-29 years respectively were more infected $\{13.3 \%\}$ than others. Among this same age group, Ikeme [7] reported Chlamydia trachomatis prevalence of $33.3 \%$ and $21.4 \%$ respectively in both student and non student populations. Studies in various cities in Nigeria produce divergent reports of Chlamydia trachomatis prevalence. A study in Lagos reported as high as $51.0 \%$ prevalence of Chlamydia trachomatis among pregnant and non pregnant women [10] while Olayede [22] reported prevalence rate of $18.2 \%$ in the same city. In Jos, North Central Nigeria, Mawak [23] reported a high prevalence rate of 56.1\% among the tested population with females in the age range 25-29 years having the highest prevalence rate followed by the age group 20-24 years with early commencement of sexual activities as one of the major risk factors. Tukur [16] reported 38.3\% prevalence rate among females with tubal infertility and $13.3 \%$ among the control group in Zaria, Northern Nigeria. In Abeokuta Ogun state southwest Nigeria, Ogiagwa [24] reported a prevalence rate of $9.8 \%$ among males and females attending fertility clinic with the age group 31-40 years having the highest prevalence rate, the same age group reported by Okoro [4]. Females were $11.6 \%$ while males were $6.5 \%$,

Wariso [25] reported a prevalence rate of $11.0 \%$ among University female students in Port Harcourt, Southern Nigeria and in Calaber, Inyang-Etoh [26] reported a prevalence rate of $22.0 \%$ among women attending infertility clinic and only $2.0 \%$ among the control group with the age group 18-25 years having the highest prevalence rate. Globally, 2010 report put female STD Chlamydia at $3.8 \%$ and male figures at $2.5 \%$ [19].

The differences in these reports even in the same city means that the method of testing for Chlamydia trachomatis may be playing a significant role. Batool [28] reported $13.8 \%$ prevalence rate among infertile women and $11.1 \%$ among fertile women using polymerize chain reaction and $8.6 \%$ and $4.9 \%$ respectively among the same population using serologic method. However, the reason may also have to do with the study population and risk factors associated with each group, for instance, studies among patients presenting with symptoms of sexually transmitted infections or among patients with multiple sexual partners would obviously produce higher prevalence rates than studies among healthy or asymptomatic populations. Factors such as age, sexual history and the presence or absence of other infections play significant roles. Some studies have suggested that women infected with Chlamydia are up to five times more likely to become infected with HIV if exposed and vice versa [29].

Furthermore, 16 patients in our study have titres of 1:16. This low level of detectable IgG antibodies could represent residual antibodies from a previous infections and not active Chlamydia infections.

Higher prevalence rate of Chlamydia in females compared to males could be as a result of the fact that Chlamydia infection is more asymptomatic in females than in males and could be easily detected and treated in males than in females.

Also the higher prevalence rate of Chlamydia in the age range 20-29 years represents the sexually active age group [30] who are most likely to have multiple sexual partners or likely to have partners who in turn have multiple sexual partners.

\section{Conclusion And Recommendations}

The finding of Chlamydia trachomatis in relatively healthy individuals indicates that this sexually transmitted disease with its dangerous consequences pass unnoticed in our population and if left untreated in women, it can cause complications such as pelvic inflammatory disease which can lead to ectopic pregnancies and infertility, and in men, untreated infections can cause inflammation of the testicles and prostate which can also lead to infertility [15].

To save families from the trauma of infertility occasioned by Chlamydia, effort should be made to routinely screen people at risk and positive cases treated accordingly. Sexual partners of infected individuals should also be treated.

Laboratories should use testing methods that are comparatively sensitive, specific and cost effective for the diagnosis of Chlamydia trachomatis

Young men and women should be enlightened on safe sex practices to reduce cases of sexually transmitted Chlamydia infections 


\section{References}

[1]. LM. Prescott, JP. Harley, D. Aklein, Microbiology, 4th edn (USA: WBC/Mc-graw hill companies, 1999). Human diseases caused by other bacteria (Chlamydia, Mycoplasma, Rickettsia), Dental and nosocomial infections; p. 8002.

[2]. K. Talaro and A. Talaro, Foundations of Microbiology 2 (USA, WCB/Mc Graw-Hill 1996).

[3]. RR. Ingalis, PA. Rice, N. Qureshi, K. Takayama, JS. Lin, DT. Golenback, The inflammatory cytokine response to Chlamydia trachomatis infection is endotoxin mediated Infect Immun, 1995, 63, 3125-3130.

[4]. LE. Okoror, DE. Agbonlahor, FI. Esumeh, and PI. Umolu, Prevalence of Chlamydia in patients attending gynecological clinics in south eastern Nigeria Afr Health Sci, 2007, 7(1), 18-24.

[5]. RW. Peeling, RL. Bailey, DJ. Conway, AEC. Holland, J. Ousman, CW. Hilton, CWM. David, Antibody resistance to the 60KDA Chlamydia heat shocked protein is as associated with scaring trachoma Journal of infectious diseases, 1998, 177, $256-259$.

[6]. BR. Jones, LH. Collier, and CH. Smith, Isolation of virus from inclusion blennorrhoea Lancet, 1959, 1, 902-905.

[7]. A C. Ikeme, H U. Ezegwui, L C. Ikeako, E. Agbata, I. Agbata, Seroprevalence of Chlamydia trachomatis in Enugu, Nigeria Niger J Clin Pract, 2011, 14, 176-80.

[8]. KM. Freund, CA. Buttlar, C. Giuampaolo, RS. Phillips, Aronson, MA. Moskowitz, The use of cervical cytology to identify woman at risk for chlamydial infection, Am J Prev Med, 1992, 8:292-297.

[9]. J. Schachter, E. Stoner, J. Moncada, Screening for chlamydial infections in women attending family planning clinics-Evaluation of presumptive indicators for therapy West J Med, 1983, 138, 375-379.

[10]. LE. Okoror, SA. Omilabu, J. Fadojutimi, V. Nsongkhai, Seroepidemiological survey of Chlamydia in patients attending pre and post natal clinic at the College of Medicine of the University of Lagos, Nigeria Book of Abstract of the 24th annual conference of the Nigerian Society for Microbiology, 2000.

[11]. MA. Chernesky, The laboratory diagnosis of Chlamydia trachomatis infection Can J Infect Dis Med Microbiol, 2005, 16(1), 39-44.

[12]. RC. Brunham, J. Kimani, J. Bwayo, G. Maitha, I. Maclean, CL. Yang, CX. Shen, S. Roman, NJD. Nagelkerke, M. Cheang, and FA. Plummer, The epidemiology of Chlamydia trachomatis within a sexually transmitted diseases core group, J. Infect. Dis, 1996, 173, 950-956.

[13]. T. Anttila, P. Saikku, P. Koskela, A. Bloigu, J. Dillner, I. Ikäheimo, Serotypes of Chlamydia trachomatis and risk development of cervical squamous cell carcinoma JAMA 2001, 285, 47-51.

[15]. JA. McGregor and JI. French, Chlamydia trachomatis infection during pregnancy Am J Obstet.Gynecol, 1991, 164, 1782-9.

[29]. T. Wong, A. Singh, J. Mann, L. Hansen, S. McMahon, Gender differences in bacterial STIs in Canada BMC Women's Health, 2004, 4(1): S26.

[38]. I. Tukur, S O. Shittu, A M. Abdul, A case control study of active genital Chlamydia trachomatis infection among patients with tubal infertility in northern Nigeria Trop Doct, 2006, 36(1) 14-16.

[40]. D. Williams, D. Churchill, Ulcerative proctitis in men who have sex with men: an emerging outbreak. BMJ, 2006, 332 (7533), 99100. doi:10.1136/bmj.332.7533.99. PMC 1326936. PMID 16410585.

[41]. World Health Organization, Global prevalence and incidence of selected curable sexually transmitted infections, Overview and estimates. Geneva: WHO, 2001.

[42]. T. Vos, Years lived with disability (YLDs) for 1160 sequelae of 289 diseases and injuries 1990-2010: a systematic analysis for the Global Burden of Disease Study 2010 Lancet, 2012380 (9859), 2163-96.

[43]. R. Lozano, Global and regional mortality from 235 causes of death for 20 age groups in 1990 and 2010 : a systematic analysis for the Global Burden of Disease Study 2010 Lancet, 2012; 380 (9859), 2095-128. doi:10.1016/S0140-6736(12)61728-0. PMID 23245604

[44]. Incidence, Prevalence, and Cost of Sexually Transmitted Infections in the United States CDC Fact Sheet, National Center for HIV/AIDS, Viral Hepatitis, STD, and TB Prevention, Division of STD Prevention, Centers for Disease Control and Prevention 1600 Clifton Rd. Atlanta, GA 30333, USA 800-CDC-INFO (800-232-4636) TTY: (888) 232-6348, 2013

[45]. OAO. Oloyede, TA. Fakoya, AA. Oloyede, AM. Alayo, Prevalence and Awareness about Chlamydial Infection in Women Undergoing Infertility Evaluation in Lagos, Nigeria International Journal of Health Research, 2009, 2(2), $157-162$.

[46]. JD. Mawak, N. Dashe, YA. Agabi, BW. Panshak, Prevalence of Genital Chlamydia trachomatis Infection Among Gynaecologic Clinic Attendees in Jos, Nigeria Shiraz E-Medical Journal, 2011, 12(2)

[47]. IO. Ogiogwa, BO. Motayo, PO. Okerentugba, HC. Innocent-Adiele, Y. Tafeng, CC. Onoh, JC. Nwanze, IO. Okonko, Detection of Chlamydia trachomatis Antigen among Attendees of a Fertility Clinic in Abeokuta, Ogun State Nigeria Researcher, 2012, 4(4), 96100 .

[48]. K T. Wariso, J. Odigie, S. Eyaru, Prevalence of Chlamydia trachomatis Infection among Female Undergraduates of the University of Port Harcourt Using Strand Displacement and Amplification [SDA] Technique The Nigerian Health Journal, 2012, 12(2), 35-38.

[49]. P C. Inyang-Etoh, G I. Ogban, E C. Inyang-Etoh, M F. Useh, S J. Etuk, Prevalence of Chlamydia trachomatis Infection among Women attending infertility Clinics in Calabar, Nigeria Nigerian Journal of Health and Biomedical Sciences, 2009, 8(1). DOI: http://dx.doi.org/10.4314\%2Fnjhbs.v8i1.47611

[50]. JV. Dacie and SM. Lewis, Practical Haematology (Churchill Livingstone, 1994).

[51]. R. Batool, C T. Leili, H. Fedyeh, R. Fatemeh, S. Mamak, R S. Abbas, D. Faezeh, A M. Mehdi, A. Soheila, Prevalence of Chlamydia trachomatis Infection in Fertile and Infertile Women; A Molecular and Serological Study J Reprod Infertil. 2009, 10(1), 32-41.

[52]. J. Debattista, C. Clementson, D. Mason, J. Dwyer, S. Argen, C.Wood ward, Screening for Neisseria gonorrhea and Chlamydia trachomatis at entertainment venues among men who have sex with men SEX Trans Dis. 2002, 29, $216-21$.

[53]. Public Health Agency of Canada, 2002 Canadian sexually transmitted infections surveillance report, Can Commun Dis Rep. 2005, 31(2), 1-39. 